\title{
Emerging Acute Chagas Disease in Amazonian Brazil: Case Reports With Serious Cardiac Involvement
}

\author{
Ana Yecê das Neves Pinto ${ }^{1,2}$, \\ Sebastião Aldo da Silva Valente ${ }^{1}$ \\ and Vera da Costa Valente ${ }^{1}$
}

\author{
Parasitology Department of the Evandro Chagas Institute ${ }^{1}$ \\ Pará State University², Belém/PA Brazil
}

\begin{abstract}
Four cases of serious cardiac attacks by autochthonous Trypanosoma cruzi infection from the Brazilian Amazon are reported; three of them occurred in micro-epidemic episodes. The manifestations included sudden fever, myalgia, dyspnea and signs of heart failure. Diagnosis was confirmed by specific exams, especially QBC (Quantitative Buffy Coat) and natural xenodiagnosis. Despite treatment with benznidazol, three patients died with serious myocarditis, renal failure and cardiac tamponade. The authors call attention to the emergence of this disease and reveal a previously unknown pathogenicity of $T$. cruzi strains in this area, added to a non-usual transmission form.
\end{abstract}

Key Words: Chagas disease, trypanosomiasis, cardiovascular, Brazilian Amazon, myocarditis.

American Trypanosomiasis (Chagas' disease) is an endemic disease of the American continent. Several countries of South America, including Brazil, maintain active control programs for the disease and for limitation of vectorial transmission. In endemic areas of Brazil, Chagas disease presents clinically as chronic cases resulting from past infections, and sporadic acute cases following transmission by transfusion, organ transplantation or immunodeficiency [1].

Despite the great biodiversity of the Amazon region and the indication that various classes of mammals and triatomine bugs can harbor species of $T$. cruzi [2-4], this region has been an area relatively free of the disease. However, some reports since 1996 in this area have demonstrated signs that it is becoming endemic [5-7]. The occurrence of family micro-epidemic episodes,

Received on 22 August 2004; revised 26 November 2004. Address for correspondence: Dr. Ana Yecê das Neves Pinto, Chagas Disease Program, Department of Parasitology, Evandro Chagas Institute. Zip code: 67.030.070, BR 316 Highway, Ananindeua City, Pará, Brazil. Phone number: 55+ 91 2142150/ 55+912114439; Fax number: 55+ 912142043.

E-mail: ayece@iec.pa.gov.br. Home page:www.iec.pa.gov.br

The Brazilian Journal of Infectious Diseases 2004;8(6):454-460 (C) 2004 by The Brazilian Journal of Infectious Diseases and Contexto Publishing. All rights reserved. probably following oral contamination, and the prevalence of clinical signs of the acute form of Chagas disease have been noted [5,8,9].

In endemic areas in general, acute and serious cases of Chagas disease have shown myocardial involvement in about $80 \%$ of the infected individuals. Mortality rates of $2 \%$ to $7 \%$ are described during an acute crisis and the mortality is higher in children. Fatal cases of myocarditis with disseminated and diffuse foci have been observed. The lesions are directly related to parasite multiplication and the tissue forms of Trypanosoma cruzi within the myocytes, causing disruption and liberation of several kinds of inflammatory mediators. These lesions occur in the contractible myocytes and in the conduction system of the heart [10].

In the Amazon Region, the mortality rates due to Chagas disease are uncertain, and there have been a growing number of fatal cases since 1996 [5]. However, we have recorded an average of 25 cases in rural and urban areas annually and there has almost invariably been heart involvement [11].

We describe four cases of serious acute myocarditis, three of them fatal. Two occurred during a microepidemic in October 1999 and one as an isolated case in September 2000. All three patients were 
undoubtedly infected by T. cruzi in the State of Pará in the Amazon Region. The Ethical Committee of the Evandro Chagas Institute approved this study, and the patients' families agreed (informed consent) in writing to this publication.

\section{Cases}

LCF was a 32 year-old male teacher, resident in the municipality of Abaetetuba, State of Pará. On September 2000, the patient noticed sudden and recurrent fever, followed by arthralgias, myalgias and dyspnea. A few days later, his condition worsened and he complained of continuous chest pain spreading towards the left arm. At this time, he was transferred to an Intensive Care Unit (Belém city) with chest pain, and apparently anterior myocardial wall ischemia. Later, however, this diagnosis was not confirmed and pericardial effusion became evident. Clinical examination showed signs of congestive heart failure and an initial ECG showed sinus rhythm, normal QRS axis, and inverted T waves from V1 to V6 (Table 2). Chest radiography showed cardiomegaly. Echocardiogram indicated left ventricle enlargement and pericardial effusion. After four days in ICU, he required a temporary pacemaker and the diagnosis of acute Chagas' disease was considered based on the registry of several cases of this disease in his municipality at the same time. Blood culture showed intense growth of epimastigote forms of $T$. cruzi. He received oral benznidazol treatment (two tablets of $100 \mathrm{mg}$ twice a day); however, the patient developed cardiogenic shock and renal failure and died 45 days following the beginning of the symptoms. The family did not allow necropsy.

Cases 2, 3 and 4 occurred as a familiar microepidemic episode, during October 1999, in a village near of Cametá, Pará state, Brazil. This episode involved a father and his two daughters.

RGS, a 50 year-old male farmer, presented with high fever, followed by chills, headache, cough, dyspnea and swelling of the legs. These symptoms occurred simultaneously with the illness of his two daughters. He was admitted to the local hospital, where a leishmaniasis indirect immunofluorescent antibody test (IFAT-IgG anti-leishmania 1/10,240) was positive. The diagnosis of visceral leishmaniasis was made and treatment with intravenous glucantime $13.1 \mathrm{~mL} /$ daily was initiated. He remained on this treatment for 13 days. As his symptoms progressed to congestive heart failure, he was transferred to Belém. Two days later, he was admitted to the Intensive Care Unit with cardiac tamponade, hypotension and acute renal failure. He required pericardiocentesis, endotracheal intubation, mechanical ventilation and peritoneal dialysis. He recovered from a cardiac arrest but developed severe ventricular tachycardia and died 40 days after the initial symptoms. The main exams that summarized the diagnosis of Chagas disease are shown in Table 1.

R.M.S, an 18 year-old female, showed intermittent fever, arthralgias and chills, at the same time as her father. Blood tests for malaria were negative. She developed chest pain, progressive dyspnea and swelling of the legs, and was hospitalized. After 13 days, a leishmaniasis indirect immunofluorescent antibody test (IFAT-IgG anti-leishmania 1/320) was positive and treatment with intravenous glucantime $9.4 \mathrm{~mL}$ daily was introduced. She did not improve with the treatment, so she was transferred to Belém, where severe pericardial effusion was seen on echocardiogram, and the glucantime was discontinued. A diagnosis of Chagas disease was then made, based on the febrile illness, congestive heart failure and serological and epidemiological data. Direct examination of fresh blood, stained thick blood films and QBC were negative. Later, however, natural xenodiagnosis using 40 third or fourth stage $T$. infestans nymphs from the Chagas disease Laboratory of Evandro Chagas Institute was positive. (Table 1)

RMS, a 22 year-old female, presented with the same symptoms as her father and sister. She was admitted to the local hospital with high fever, intense abdominal pain and vomiting. A leishmaniasis indirect immunofluorescent antibody test (IFAT-IgG antileishmania $1 / 10,240$ ) was positive, and treatment with intravenous glucantime $10.5 \mathrm{~mL} /$ daily was initiated. After three days, she developed congestive heart 
failure, hypotension, renal failure, and was admitted together with her father and sister to the same hospital in Belem. In view of the other case histories of her relatives, she was suspected to have Chagas' disease and the glucantime was discontinued. In addition to the treatment of congestive heart failure, she received Benznidazol (100 mg three times a day). She developed a right bundle branch block on ECG, and cross sectional echocardiography showed a large pericardial effusion (Table 2). She underwent two pericardiocenteses. Nevertheless, her condition worsened and she died of cardiac tamponade after 10 days of hospitalization. In this case, an autopsy was carried out, and myocardial fragments were sampled by routine hematoxylin and eosin staining. An interstitial edema and diffuse inflammatory infiltrate of monocytes were present, with dissociation of cardiac tissue. Rare parasite nests of amastigote forms of $T$. cruzi were found. Histological sections of these nests were stained with peroxidase containing $T$ cruzi antibodies, and these revealed parasitic antigens located in necrotic foci of myocytes and in intracellular macrophages (Figure 1).

\section{Discussion}

Chagas disease in Amazonian Brazil has previously been reported in several family micro-epidemic episodes. Since the first three cases of human autochthonous Chagas' disease described by Shaw et al., in Belém city, state of Pará, 148 cases have been recorded by the Instituto Evandro Chagas, with an average of six cases per family episode. A total of 121 cases were acute, with five deaths; 67 cases out of the 121 were associated with family micro-epidemic episodes; and this fact suggests transmission by the oral route [9]. In our cases 2, 3 and 4, transmission may have occurred by oral route, based on the simultaneity of the onset symptoms. Though, case 1 may have resulted from a vectorial transmission, we did not find a port of entry.

As a rule, the course of disease is benign after specific treatment, in spite of late therapy due to a late diagnosis. However, Chagas disease in the Amazon area has also been described as having a more serious outcome. Viana et al. reported three cases occurring in children of the same family, in the municipality of Sena Madureira, state of Acre, which is part of the Amazon Region. These children developed severe congestive heart failure, and a five-year-old child died after 15 days of disease. Direct blood examination showed a high parasitemia, and amastigoste forms of T. cruzi were seen in the cardiac muscle [12]. In endemic areas, the acute form of Chagas disease exhibits a relatively benign course, with total cessation of symptoms, concomitantly with clearance of parasites, as shown by direct parasitological examination. However, cardiac involvement in children is more serious and the mortality rate is higher (5\%) [1].

In our cases, the mortality rate was unusually high (3 out of 4). Case 1 was long considered as having coronary heart disease; and this contributed to the delay in making a correct diagnosis and commencing the appropriate therapy. The other three cases, within the same family, had the clinical management delayed due to the false positive titers of IFAT-IgG anti-leishmania. The treatment with glucantime probably caused cardiotoxicity in a heart already affected by an intense inflammatory process, leading to a stormy clinical course $[13,14]$. The one who survived (case 3 ) had low titers of anti-leishmania IFAT-IgG, compared with the others, who had exceedingly high titers. Although an unspecific response, this may have induced an intense immunological reaction in cases 2 and 4, consistent with a huge antigenic stimulus. The outcome of these cases is further evidence that the pathogenicity of infection with strains of T. cruzi in the Amazon Region are the result of contamination by the oral route, through which the disease may be more severe than with other modes of transmission.

Camandaroba et al. studied two T. cruzi strains: a Colombian (Biodeme Type III, Z1) and a Peruvian strain (Byodeme Type I, Z2b); he showed that the former was more infectious and pathogenic in mice infected by the gastrointestinal route [15]. We already know that most of the cases that have occurred in the Amazon Region, in micro-epidemic episodes, have 
Table 1. Diagnostic and complementary examinations seen in acute myocarditis in four Amazonian cases of Chagas disease

\begin{tabular}{|c|c|c|c|c|}
\hline \multirow{2}{*}{ Tests } & \multicolumn{4}{|c|}{ Cases/ results } \\
\hline & Case 1 & Case 2 & Case 3 & Case 4 \\
\hline Direct microscopic exam & Positive & Negative & Negative & Negative \\
\hline Thick blood film & Positive & Negative & Negative & Negative \\
\hline QBC* & Positive & Negative & Negative & Negative \\
\hline Xenodiagnosis & Positive & Positive & Positive & Positive \\
\hline Trypanosoma cruzi blood culture & Positive & ND & ND & Negative \\
\hline IFAT $^{\dagger}$ IgM anti- $T$. cruzi & $1 / 80$ & $1 / 40$ & $1 / 80$ & $1 / 1280$ \\
\hline IFAT IgG anti-T. cruzi & $1 / 160$ & $1 / 360$ & $1 / 160$ & $1 / 1280$ \\
\hline Count of leucocytes (k/ul) & 8900 & 10500 & 4300 & 14100 \\
\hline Lymphocytes $(\%)$ & 23 & 11 & 24 & 14 \\
\hline Atypical lymphocytes & Absent & Absent & Absent & Absent \\
\hline $\operatorname{Hemoglobin}(\mathrm{g} / \mathrm{dL})$ & 10.3 & 8.5 & 9.8 & 8.5 \\
\hline Creatinine (mg/dL) & 2.0 & 6.2 & 0.7 & 6.3 \\
\hline $\mathrm{AST}^{\ddagger}\left(\mathrm{UI} / \mathrm{mL}^{\dagger}\right)$ & 93 & 93 & 43 & 53 \\
\hline
\end{tabular}

$*$ QBC $=$ Quantitative Buffy Coat. ${ }^{\dagger}$ IFAT $=$ Immunofluorescent Assay Test. $\ddagger$ AST $=$ Arginine Spartate Transferase. $\mathrm{ND}=$ Not done.

Table 2. Electrocardiograms, echocardiograms and chest $x$-rays in acute myocarditis among cases of Amazonian Chagas disease

\begin{tabular}{|c|c|c|c|c|}
\hline \multirow{2}{*}{ Exams } & \multicolumn{4}{|c|}{ Patient results } \\
\hline & Case 1 & Case 2 & Case 3 & Case 4 \\
\hline ECG1 & $\begin{array}{l}\text { ST-segment elevated, T wave } \\
\text { V1 to V6; } 12 \text { extra-systoles } \\
\text { ventricular/minute }\end{array}$ & RBBB* & Bradycardia & Tachycardia \\
\hline ECG2 & ND & RBBB & Normal & ND \\
\hline Echocardiogram & $\begin{array}{l}\text { Dilatation of left ventricle, } \\
\text { reduced contractibility in } \\
\text { apical area of right ventricle }\end{array}$ & $\begin{array}{l}\text { Severe } \\
\text { pericardial } \\
\text { effusion; diastolic } \\
\text { restriction }\end{array}$ & $\begin{array}{l}\text { Severe } \\
\text { pericardial } \\
\text { effusion }\end{array}$ & $\begin{array}{l}\text { Pericardial } \\
\text { effusion, } \\
\text { moderate } \\
\text { valvular } \\
\text { regurgitation }\end{array}$ \\
\hline Chest X-ray & Cardiomegaly & ND & Cardiomegaly & $\begin{array}{l}\text { Cardiomegaly; } \\
\text { lung congestion }\end{array}$ \\
\hline
\end{tabular}

$* \mathrm{RBBB}=$ right bundle branch block.

$\mathrm{ND}=$ Not done. 
Figure 1. Myocardial fragment obtained from necropsy of acute myocarditis case. Panel A shows a rare parasite nest of amastigote forms of Trypanosoma cruzi in cardiac myocytes. H\&E, OM 400x. Panel B shows sections of the heart stained with peroxidase containing anti-T. cruzi antibodies purified in rabbits, using as secondary antibody a biotinylated IgG anti-rabbit produced in goats (Vectastain Elite $\mathrm{ABC}$ Kit), revealed parasite antigens of amastigote forms of $T$. cruzi with specific markers, which are partially broken, located at necrosis foci in cardiac myocytes and in intracellular macrophages.
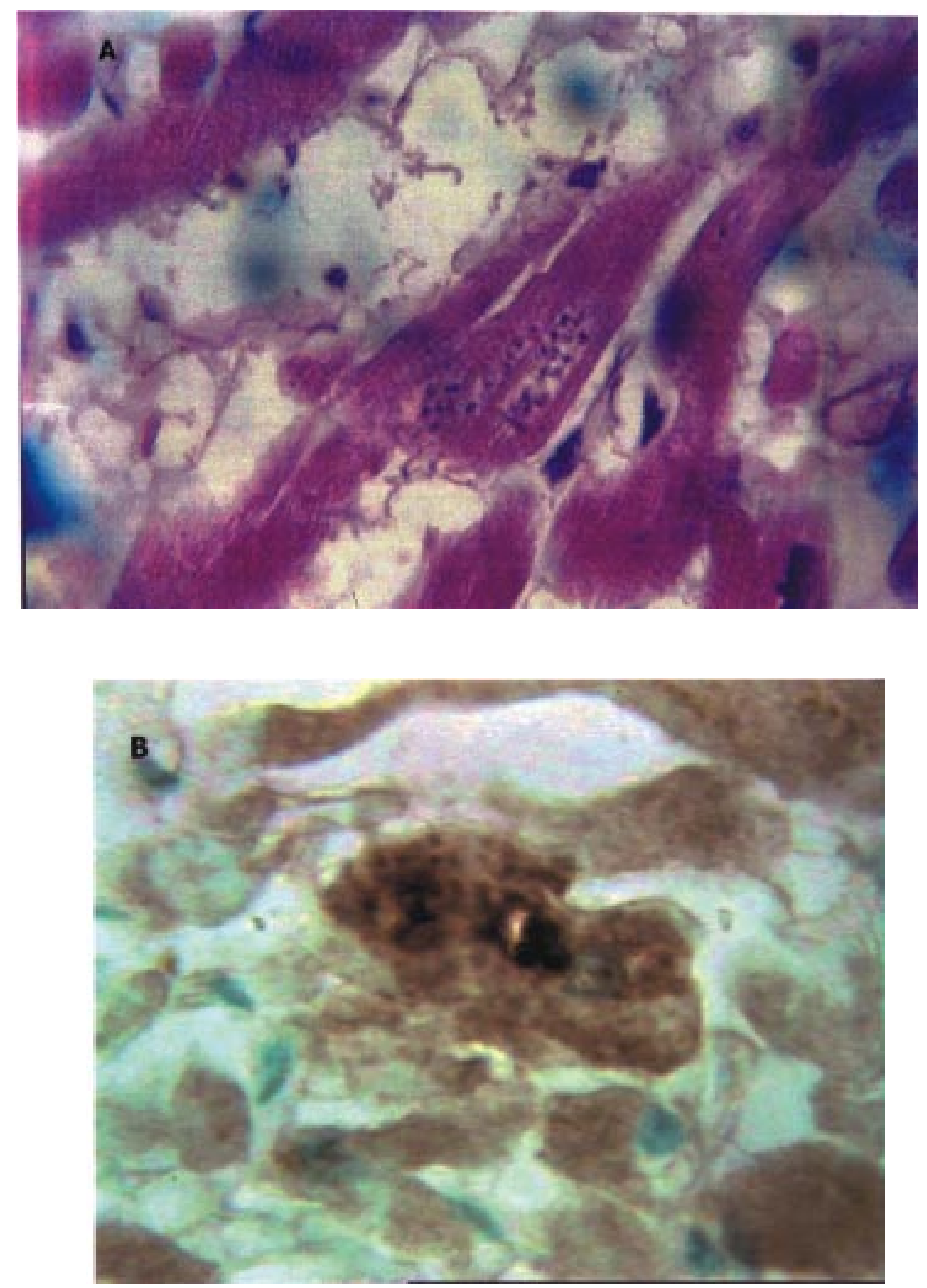
resulted from the ingestion of food contaminated with feces of sylvatic hosts or vectors that harbor T. cruzi strains that are more adapted to the sylvatic cycle, like the Colombian strain.

Another important report of cardiac involvement in T. cruzi infection in a non-endemic area occurred in the city of Cayenne, French Guiana. In this city, four acute cases of disease also revealed severe heart failure. Echocardiography showed severe impairment of systolic function and asymptomatic pericardial effusion. One patient died with cardiogenic shock and the other three recovered with treatment [16].

The authors draw attention to the serious problem of American Trypanosomiasis in the Amazon Region, where the number of human cases is on the rise and the mortality rates are unknown. Despite the reports of the same species of wild triatomine bugs in the Brazilian Amazon [3, 4], we and other authors have suggested that triatomine domiciliation is not an essential step for the installation of Chagas' disease in this region $[6,9,17,18]$.

The Brazilian scientific community should be aware of this emergent disease in the Amazon region in order to reinforce preventive measures in its control; these may be distinctly different from those applied in endemic areas in other parts of Brazil. Indeed, Amazonian Chagas' disease might well be regarded as a relatively new clinical entity that should be more studied and added to the list of diseases of modern worldwide concerns for epidemiological surveillance.

\section{Acknowledgements}

Financial support was provided by the Evandro Chagas Institute, National Health Foundation/Health Ministry of Brazil. Special thanks to Dr. Sonia Andrade from the Centro de Pesquisas Gonçalo Muniz/ FIOCRUZ for the histopathological exams. We thank Ralph Lainson, Alberto Gomes Ferreira and Sheila Ferreira for reviews of the manuscript. Thanks to Carlos Alberto Rodrigues, Francisco dos Santos Gomes, Gilberto C. Rodrigues de Souza, José Elson Abud and Leonardo S. Carvalho from Instituto Evandro Chagas, to Dr. Renata K.S. Pantoja and José Floriano Ferreira from João de Barros Barreto Hospital. Distrito Sanitário/FUNASA and Municipal Cities hall of Cametá and Abaetetuba, PA, for their support.

\section{References}

1. Amato Neto V., Shikanai Yasuda M.A., Amato V.S. Doença de Chagas Aguda. In: Dias J.C.P. and Coura J.R., eds. Clínica e Terapêutica da Doença de Chagas. Uma abordagem prática para o clínico geral. Rio de Janeiro; 1997:127-33.

2. Deane L. Animal reservoirs of Trypanosoma cruzi in Brazil. Rev Bras Malariol 1964;16:27-48.

3. Lainson R., Shaw J.J., Fraiha H., et al. Chagas disease in the Amazon Basin 1. Trypanosoma cruzi infections in silvatic mammals, triatomine bugs and man in the State of Pará, north Brazil. Trans R Soc Trop Med Hyg 1979;73:193-204.

4. Miles M.A., Arias J.R., Souza A.A. Chagas disease in the Amazon basin. V. Peri-urban palms habitats of Rhodnius robustus and Rhodnius pictipes triatominae vectors of Chagas disease. Mem Inst Oswaldo Cruz 1983;78:391-8.

5. Coura J.R., Junqueira A.C.V., Fernandes O., et al. Emerging Chagas disease in Amazonian Brazil. Trends Parasitol 2002;18:171-6.

6. Fraiha Neto H., Valente S.A.S., Valente V.C., Pinto A.Y.N. Doença de Chagas - endêmica na Amazônia? Rev Academ Med (Pará) 1995;6:53-7.

7. Valente S.A.S., Valente V.C., Pinto A.Y.N., Crescente J.A.B. Doença de Chagas. In: Veronesi R, Focaccia R.Tratado de Infectologia. 2nd ed. São Paulo; 1997. p.1501-2.

8. Shaw J.J., Lainson R., Fraiha H. Considerações sobre a epidemiologia dos primeiros casos autóctones de doença de Chagas registrados em Belém, Pará, Brasil. Rev Saude Publica 1969;3:153-7.

9. Valente S.A.S., Valente V.C., Frahia Neto H. Considerations on the epidemiology and transmission of Chagas disease in the Brazilian Amazon. Mem Inst Oswaldo Cruz 1999;94(supl.1):395-8.

10. Andrade Z.A. Immunopathology of Chagas disease. Mem Inst Oswaldo Cruz 1999;94 (sup.1):71-80.

11. Pinto A.Y.N., Harada G.S., Valente V.C., et al. Acometimento cardíaco em pacientes com doença de Chagas aguda em microepidemia familiar, em Abaetetuba, na Amazônia brasileira. Rev Soc Bras Med Trop 2001;34:413-19.

12. Viana S., Farias E., Lima F., et al. Doença de Chagas no Estado do Acre, registro de 3 casos de Miocardiopatia Chagásica Aguda autóctone no Município de Rio Branco,1993. Rev Soc Bras Med Trop 1994;27(suppl.I):77. 
13. Chulay J.D., Flenckenstein L., Smith D.H. Pharmacokinetics of antimony during treatment of visceral leishmaniasis with sodium stibogluconate or meglumine antimoniate. Trans R Soc Trop Med Hyg 1988;82:69-72.

14. Ribeiro A.L., Drummond J.B., Volpini A.C., et al. Electrocardiographic changes during low-dose, shortterm therapy of cutaneous leishmaniasis with the pentavalent antimonial meglumine. Braz J Med Biol Res 1999;32:297-301.

15. Camandaroba E.L.P., Pinheiro Lima C., Andrade S.G. Oral transmission of Chagas disease: importance of Trypanosoma cruzi biodeme in the intragastric experimental infection. Rev Inst Med Trop Sao Paulo 2002;44:97-103.

16. Carme B., Aune I., Nguyen G., et al. Four cases of acute chagasic myocarditis in French Guiana. Amer J Trop Med Hyg 2001;64:162-3.

17. Coura J.R., Junqueira A.C., Boia M.N., Fernandes O. Chagas disease: from bush to huts and houses. Is it the case of the Brazilian Amazon? Mem Inst Oswaldo Cruz 1999;94(supl.1):379-84.

18. Teixeira A.R.L., Monteiro P.S., Rebelo J.M., et al. Emerging Chagas Disease: Trophic network and cycle of transmission of Trypanosoma cruzi from palm trees in the Amazon. Emerg Infect Dis 2001; 7:100-12. 